\title{
O USO DOS GÊNEROS CONTO E CURTA-METRAGEM COMO ESTRATÉGIA PARA A FORMAÇÃO DO LEITOR LITERÁRIO
}

\author{
THE USE OF THE GENRES SHORT STORY AND SHORT FILM AS A \\ STRATEGY FOR THE FORMATION OF THE LITERARY READER
}

\author{
Roberto Barbosa Costa Filho ${ }^{1}$ \\ Márcia Tavares ${ }^{2}$
}

Recebido em: 06/06/2020

Aprovado em: 19/09/2020

\begin{abstract}
RESUMO: Como defendido pelos documentos parametrizadores da educação básica, especialmente aqueles relativos ao Ensino Médio, a literatura deve ser trabalhada em sala de aula a partir de uma perspectiva que proporcione práticas de letramento literário, com experiências de leitura efetiva do texto literário e busca da fruição estética (BRASIL 2006; 2018). Diante desse cenário, este trabalho tem como objetivo apresentar estratégias para a formação de leitores literários por meio do uso dos gêneros conto e curta-metragem. Materializado através de um Estágio Supervisionado de Literatura no Ensino Médio, a experiência que suscita o trabalho utilizou-se do conto "Restos do carnaval", de Clarice Lispector, e do curta-metragem "Uma flor", inspirado nesse texto, enquanto estratégia para a construção do letramento literário de leitores em formação. Dessa forma, as bases teóricas do trabalho centram-se nas contribuições sobre letramento literário e leitura literária (COSSON, 2006; BARBOSA, 2011; BORGES; PAES, 2017), sobre os gêneros conto (ABDALA JÚNIOR, 1995; GOTLIB, 2006) e curta-metragem (ALCÂNTARA, 2014) e sobre estratégias de aprendizagem (BORUCHOVITCH, 1999; FIGUEIRA, 2006) e de leitura (KLEIMAN, 2013; KOCH; ELIAS, 2006; ROJO, 2009). Mais do que apresentar a experiência enquanto possibilidade para novas práticas de ensino e (res)significações, espera-se que o trabalho possa contribuir para (re)pensar: o espaço da literatura em sala de aula; as estratégias que podem ser utilizadas para a formação de leitores; e a articulação de novas linguagens, como a audiovisual, em sala de aula.
\end{abstract}

Palavras-chave: Leitura Literária. Estratégias. Formação de leitores.

\begin{abstract}
As defended by the basic education parametrizing documents, especially those related to High School, literature should be worked in the classroom from a perspective that provides literary literacy practices, with experiences of effective reading of the literary text and pursuit for aesthetic fruition (BRASIL 2006; 2018). Thus, this paper aims to present strategies for literary readers' formation through the use of the genres short story and short movie. Materialized through a supervised literature internship in High School, the experience that gives rise to the work used the short story "Remnants of Carnival", by Clarice Lispector, and the short film "A Flower", inspired in this text, as a strategy for the construction of literary literacy of readers in formation. Therefore, the theoretical bases of the paper focus on contributions on literary literacy and literary reading (COSSON, 2006; BARBOSA, 2011; BORGES; PAES, 2017), on the short story (ABDALA JÚNIOR, 1995; GOTLIB, 2006) and short films (ALCÂNTARA, 2014) and about learning strategies (BORUCHOVITCH, 1999; FIGUEIRA, 2006) and reading (KLEIMAN, 2013; KOCH; ELIAS, 2006; ROJO, 2009). More than presenting the experience as a possibility for new teaching practices
\end{abstract}

\footnotetext{
${ }^{1}$ Mestrando pelo Programa de Pós-graduação em Linguagem e Ensino (PPGLE) da Universidade Federal de Campina Grande (UFCG) - Bolsista CAPES. Licenciado em Letras: Língua Portuguesa pela UFCG. E-mail: costafrob@gmail.com.

2 Doutora em Letras pela Universidade Federal da Paraíba (UFPB). Licenciada em Letras pela UFPB. Professora Adjunto III da UFCG e membro do quadro permanente do PPGLE da mesma universidade. E-mail: tavares.ufcg@gmail.com.
} 
and (re)meanings, it is expected that the paper can contribute to (re)thinking: the space of literature in the classroom; the strategies that can be used to form readers; and the articulation of new languages, such as audiovisual, in the classroom.

Keywords: Literary Reading. Strategies. Reader formation.

\section{APRESENTAÇÃO}

Os diversos documentos que orientam a educação básica brasileira apresentam considerações sobre o ensino de literatura. Em ordem cronológica, os Parâmetros Curriculares Nacionais para o Ensino Médio (PCNEM) sugerem que a literatura e os demais aspectos relativos à língua portuguesa devam ser trabalhados por meio de uma perspectiva maior, que é a linguagem, a fim de proporcionar uma ampla visão das suas possibilidades de uso enquanto um recurso expressivo e em relação aos contextos (natureza do texto, função, estrutura, etc.) e às condições (época, local, interlocutores, etc.) de produção e de recepção de textos (BRASIL, 2000).

Já as Orientações Curriculares para o Ensino Médio (OCEM), alguns anos depois, ampliam a abordagem literária em sala de aula, conferindo a ela as especificidades e a autonomia que lhes são próprias como objeto de conhecimento. Nessa direção, as OCEM preveem a necessidade "de formar o leitor literário, melhor ainda, de "letrar" literariamente o aluno, fazendo-o apropriar-se daquilo a que tem direito." (BRASIL, 2006, p. 54). Com isso, põe-se em destaque a perspectiva do letramento e da experiência literária, através do contato efetivo com o texto e da construção da fruição estética própria do leitor em formação. Essa perspectiva é acionada por meio da troca de significados entre texto e leitor, da ampliação de horizontes e do prazer estético (BRASIL, 2006).

Reiterando isso, a Base Nacional Comum Curricular (BNCC) para o Ensino Médio, através do campo artístico-literário, propõe a continuidade da formação do leitor literário, iniciada no Ensino Fundamental por meio de "práticas de leitura literária que possibilitem o desenvolvimento do senso estético para a fruição, valorizando a literatura e outras manifestações artístico-culturais [...], reconhecendo o potencial transformador e humanizador da experiência com a literatura." (BRASIL, 2018, p. 87). Nesse contexto, as práticas de leitura literária devem proporcionar a seleção de obras significativas para si, a fim levar o aluno a apreender níveis mais profundos de leitura dos textos e dos discursos subjacentes, além de recuperar a historicidade de produção dos textos. Essas práticas devem responder ainda a uma série de habilidades a ser contemplada, no que diz respeito ao compartilhamento de sentidos através da leitura/escuta de textos literários, à percepção de peculiaridades estruturais e estilísticas de diferentes gêneros literários, à análise de relações intertextuais e interdiscursivas entre obras e gêneros literários de um mesmo momento histórico ou de momentos diversos, dentre outras (BRASIL, 2018).

Diante desse arcabouço documental que já define claramente perspectivas para o ensino de literatura, este trabalho tem como objetivo apresentar estratégias para a formação de leitores literários por meio do uso dos gêneros conto e curta-metragem. Ele se materializa a partir de uma experiência de ensino em Estágio Supervisionado de Literatura no Ensino Médio ${ }^{3}$ do curso de Letras: Língua Portuguesa da Universidade Federal de Campina Grande (UFCG). Essa experiência ocorreu em uma escola pública de Campina Grande-PB, com o uso do conto "Restos do carnaval", de Clarice Lispector, e do curta-metragem "Uma flor", inspirado nesse texto, enquanto estratégia para a construção do letramento literário dos leitores em formação.

Esperamos que o trabalho, muito mais que apresentar essa experiência de ensino, possa ser alvo de reflexões para (re)pensar: o espaço da literatura em sala de aula, em especial do texto lite-

\footnotetext{
${ }^{3}$ Este estágio foi desenvolvido no interior das atividades do Programa de Residência Pedagógica, que tem a finalidade de implementar projetos inovadores em articulação entre teoria e prática nos cursos de licenciatura, através da parceria entre Instituições de Ensino Superior e as redes públicas de educação básica (CAPES, 2018).
} 
rário; as estratégias que podem ser utilizadas para a formação de leitores; e a articulação de novas linguagens, como a audiovisual, em sala de aula. Para isso, além desta introdução, esse texto apresenta outras quatro seções para situar teoricamente a leitura literária e os gêneros conto e curta-metragem, expor e refletir (sobre) o uso desses gêneros enquanto estratégia de formação leitora e manifestar algumas considerações finais.

\section{A LEITURA LITERÁRIA EM SALA DE AULA}

A literatura é um poderoso instrumento de educação, como bem defendido por Candido (1995), tendo em vista a possibilidade despertada por ela para compartilhar valores sociais estabelecidos, sejam eles positivos e/ou negativos para a formação humana. Conforme o estudioso, a literatura fornece um meio de vivenciar dialeticamente as problemáticas humanas, na medida em que as confirma e as nega, as propõe e as denuncia, as apoia e as combate, demonstrando o forte papel humanizador que a leitura de textos literários pode proporcionar para a formação humana e escolar.

A leitura literária deve proporcionar ao aluno a participação em variadas práticas de letramento literário, como propõem os documentos mais recentes que regem a educação básica. $\mathrm{O}$ princípio norteador do letramento literário é "a construção de uma comunidade de leitores" (COSSON, 2006, p. 47), por meio da constituição de um repertório vasto de textos. Para Cosson (2006, p. 47-48), o ensino de literatura deve efetivar um movimento contínuo de leitura, "partindo do conhecido para o desconhecido, do simples para o complexo, do semelhante para o diferente, com o objetivo de ampliar e consolidar o repertório cultural do aluno.".

No contexto escolar, a literatura deve ter o compromisso de conhecimento exigido a todo saber. Isso nos leva à importância de se desenvolver práticas centradas na leitura efetiva dos textos literários, de modo a não restringir a experiência a informações críticas, historiográficas e teóricas ou a não tomar um caminho assistemático por puro prazer. Quando destacamos a centralização na leitura literária, a entendemos como um trabalho efetivo de produção de leituras protagonizadas pelo leitor, como prática de uma construção subjetiva, fruto de um trabalho interpretativo intenso (BARBOSA, 2011). Entendemos também que, nesse contexto, ela pode ser aperfeiçoada, de modo a atingir "o olhar crítico que desagrega do texto, todos os pormenores inseridos no texto." (BORGES; PAES, 2017, p. 257). Dessa forma, a proficiência leitora a que se pode atingir em sala de aula tornará o aluno apto a lidar com situações, cada vez mais recorrentes, que exijam a criticidade ao ler textos.

Para tanto, a mediação assume um papel fundamental e é de inteira responsabilidade do professor. Como afirma Barbosa (2011), a organização do espaço, a definição clara de objetivos, a realização de perguntas para facilitação do processo interpretativo, dentre outras ações, são formas de atuação positiva para o processo de leitura. Nos pressupostos do letramento literário defendidos por Cosson (2006), a mediação deve permitir as práticas de exposição e crítica oral das leituras realizadas, como também de registro da experiência literária através de comentários, fichas de leituras, reflexões temáticas entre a obra, a realidade do aluno e a situação atual da sociedade, etc.

Pensar na mediação da leitura literária é refletir sobre o planejamento de estratégias para a sua realização em sala de aula. No campo do ensino e da aprendizagem, as estratégias são definidas como procedimentos ou atividades escolhidas para facilitar a aquisição, o armazenamento e/ou a utilização de informações (BORUCHOVITCH, 1999). Nesse sentido, a aprendizagem é vista como um processo dinâmico e ativo, no qual o aluno, por meio de uma mediação social e cognitiva com base em estratégias, deve ser levado a aprender a aprender, a recordar, a pensar, a resolver problemas (FIGUEIRA, 2006).

Nos estudos sobre leitura, estratégias são definidas como "operações regulares para abordar o texto" (KLEIMAN, 2013, p. 74), classificadas como metacognitivas ou cognitivas. Conforme Kleiman (2013), as estratégias metacognitivas seriam as operações realizadas conscientemente pelo leitor, sendo de extrema importância para a autoavaliação da própria compreensão e para a deter- 
minação de objetivos de leitura. Já as estratégias cognitivas seriam aquelas operações realizadas sem consciência pelo leitor, como o fatiamento sintático do texto. Em um processo de mediação, as estratégias metacognitivas devem ser desenvolvidas e ampliadas.

Para Koch e Elias (2006), essas estratégias são usadas para a construção de sentidos

da leitura, na interação entre autor-texto-leitor. Antecipação, hipóteses e ativação de conbecimentos são algumas estratégias exemplificadas por essas autoras. Rojo (2009) apresenta uma lista maior de estratégias "de compreensão" leitora, que seriam as atividades e/ou as capacidades acionadas para a interação com o texto e para a sua compreensão. São elas: ativação de conhecimentos de mundo; antecipação ou predição de conteúdos ou de propriedades dos textos; checagem de bipóteses; localização e / ou retomada (cópia) de informações; comparação de informações; generalizações; produção de inferências locais; produção de inferências globais (ROJO, 2009, p. 77-79).

Atrelados a essas discussões, neste trabalho, compreendemos estratégia como um conjunto de atividades, devidamente planejadas e mediadas, que promovem a leitura do texto literário, a fim de atingir objetivos pretendidos. Diante do texto, estratégia pode ser entendida ainda como as ações realizadas pelo leitor para a construção de sentidos e a obtenção da fruição estética. Uma das estratégias para a experiência aqui apresentada foi a utilização dos gêneros conto e curta-metragem para a leitura literária da obra de Clarice Lispector.

\section{O USO DOS GÊNEROS CONTO E CURTA-METRAGEM PARA A LEITURA LITERÁRIA}

Comumente, o gênero conto é caracterizado por sua brevidade em comparação a outros gêneros literários, como o romance e a novela. Essa forma breve de organizar a narrativa exige uma condensação das categorias narrativas e uma hierarquização dos fatos a serem narrados. Conforme Gotlib (2006, p. 29), no modo tradicional de construção de um conto, "a ação e o conflito passam pelo desenvolvimento até o desfecho, com crise e resolução final". Na modernidade, esse esquema permanece, fragmentando-se numa estrutura invertebrada. Dessa forma, e em consequência também das transformações sociais, a verdade universal e a representação unívoca do mundo passam a ser questionadas, o que dá lugar a enredos diluídos "nos feelings, sensações, percepções, revelações ou sugestões íntimas... [...] os mil e um estados interiores vão se desdobrando em outros." (GOTLIB, 2006, p. 30). Em Clarice Lispector, a combinação de diversos elementos da tradição e da modernidade se realiza e, certamente, é a responsável pela especificidade de sua escrita. No conto "Restos do carnaval", publicado originalmente no livro "Felicidade Clandestina" (1971), temos uma narrativa em $1^{a}$ pessoa, realizada por uma mulher aparentemente adulta, a partir de suas recordações de infância de um carnaval. Por essa razão, conforme Oliveira (2002), a narrativa ocorre em dois tempos distintos, isto é, o tempo presente, da enunciação em que a narradora adulta se põe a relembrar, e o tempo passado, da narradora criança em época de carnaval. Essa estrutura ainda confere certo tom autobiográfico à narrativa, tendo em vista também que algumas características dos acontecimentos se relacionam com a vida da escritora.

De modo introspectivo, a narrativa, que no tempo presente ocorre em uma quarta-feira de cinzas, demarca-se na dualidade entre alegria e melancolia. O distanciamento entre os dois tempos não cria uma distância emocional entre a narradora e o episódio que constitui o conto (FERREIRA, 2018). Ao contrário, deflagra uma aproximação dos sentimentos (re)vividos. Nessa relação sentimental, o texto é marcado por analogias, sentimentos distintos, conflitos e contextos sociais e familiares que devem ser percebidos para a construção de sentido(s) em sua leitura.

O curta-metragem, por sua vez, é historicamente definido com base em sua extensão, que é recorrentemente inferior a 30 minutos. Contudo, esse gênero possui particularidades discursivas próprias que o caracterizam. Conforme Alcântara (2014), o curta-metragem possui: número reduzido de personagens e de diálogos; condensação narrativa e, consequentemente, condensação de linguagem e de ação; tempo, na maioria das vezes, linear; verossimilhança com a realidade; forte 
carga emotiva e sugestiva; e desfechos, por vezes, surpreendentes. Além disso, ainda segundo o autor, é um gênero que tem relevância na veiculação de conteúdos culturais com valores educativos.

Esse gênero é um texto fílmico que "possui seus sistemas específicos de significação, compostos principalmente de imagens e sons, os quais, ao serem manipulados, por meio de planos, luzes e movimentos de câmera, além de outros, produzem determinados efeitos de sentido." (ALCÂNTARA, 2014, p. 30). No escopo do processo de ensino e de aprendizagem, esse gênero, enquanto produto audiovisual, permite a análise de narrativas de forma rica, uma vez que relaciona elementos linguísticos e extralinguísticos. Esse gênero também permite a relação com elementos socioculturais, que têm muito a enriquecer a leitura em sala de aula.

No caso específico do curta-metragem "Uma flor", este se configura, além de texto fílmico, como texto literário pela conexão direta com o conto de Clarice Lispector de que se inspira. São perceptivos os traços narrativos trazidos pelo curta-metragem, com uma trilha sonora marcante e carregada de sentimentalismo, visivelmente identificado a partir das ações das personagens, do jogo de imagens e de cores, dos focos de câmera e das mudanças auditivas. Ele quase não possui diálogos e tem duração de 11 min. e 20 seg. É uma produção da Universidade Estácio de Sá, realizada em 2009, no Rio de Janeiro, com direção de Érica Rocha e Gilson Júnior, direção de arte de Renata Freitas e elenco composto por Edson de Souza, Ilson Fernandes Júnior, Kika Farias, Natália Freitas e Samili Cunha.

Utilizados para a leitura literária em sala de aula, esses dois gêneros podem auxiliar na compreensão leitora e na construção de sentidos, em uma relação entre os textos, seus autores e os leitores. Observar um mesmo enredo sendo narrado a partir de duas mídias - texto escrito e texto fílmico - pode favorecer ainda a ação de comparação e, consequentemente, de visão crítica diante de um texto. Além disso, proporciona trabalhar como os elementos, em cada uma dessas mídias, podem possibilitar efeitos nos sentidos gerados nos leitores. Dessa maneira, a experiência que segue buscou oferecer possibilidades de construção de sentidos sobre a história da menina em sua festa de carnaval através das narrativas dos textos desses gêneros e dos elementos que os constituem, de modo a mediar estrategicamente as práticas de letramento literário dos leitores em formação.

\section{A FORMAÇÃO ESTRATÉGICA DE LEITORES LITERÁRIOS}

Como já defendido neste trabalho, as aulas de literatura devem proporcionar aos alunos práticas de letramento literário, a partir da experiência com o texto literário, em busca da construção de sentido(s) e da fruição estética. No Ensino Médio, estamos diante de leitores que, possivelmente, já possuem algumas experiências de leitura, o que pressupõe certa maturidade e senso crítico. Como determina a organização da maioria dos currículos escolares, no $3^{\circ}$ ano do Ensino Médio, o professor deve trabalhar, dentre outros, com textos produzidos e representativos do Modernismo. Em cumprimento a essa demanda, e para realização do Estágio Supervisionado, almejamos o trabalho com contos de Clarice Lispector, uma das maiores representantes da $3^{\text {a }}$ fase do Modernismo brasileiro.

De modo geral, as narrativas selecionadas tinham como personagens principais mulheres em diferentes fases da vida: em "Restos do carnaval", temos prioritariamente a mulher criança; em "Preciosidade", a mulher em transição da adolescência para a adultez; e em "Feliz aniversário", a mulher idosa. Para a leitura comparativa, selecionamos três curtas-metragens, baseados nesses textos, sendo, respectivamente: "Uma flor", "Preciosa" e "Feliz aniversário", todos disponíveis na plataforma de vídeos YouTube. Para este trabalho, contudo, focalizamos a experiência com as leitu-

\footnotetext{
4 Disponível em: https://www.youtube.com/watch?v=71r008wX30g. Acesso em: 03 mar. 2020.

5 Disponível em: https://www.youtube.com/watch?time_continue=505\&v=Na7olxbWA6Y. Acesso em: 03 mar. 2020.

6 Disponível em: https://www.youtube.com/watch?v=grQnoqgsNVA. Acesso em: 03 mar. 2020.
} 
ras do conto "Restos do carnaval" e do curta-metragem "Uma flor".

Para mediação estratégica de leitura dessas narrativas, planejamos, inicialmente, a leitura do conto, silenciosamente e em voz alta. Com o intuito de que essa leitura não tomasse um caminho assistemático, organizamos um roteiro de leitura com questões que auxiliassem para a construção de sentido(s) dos leitores. Observemo-lo:

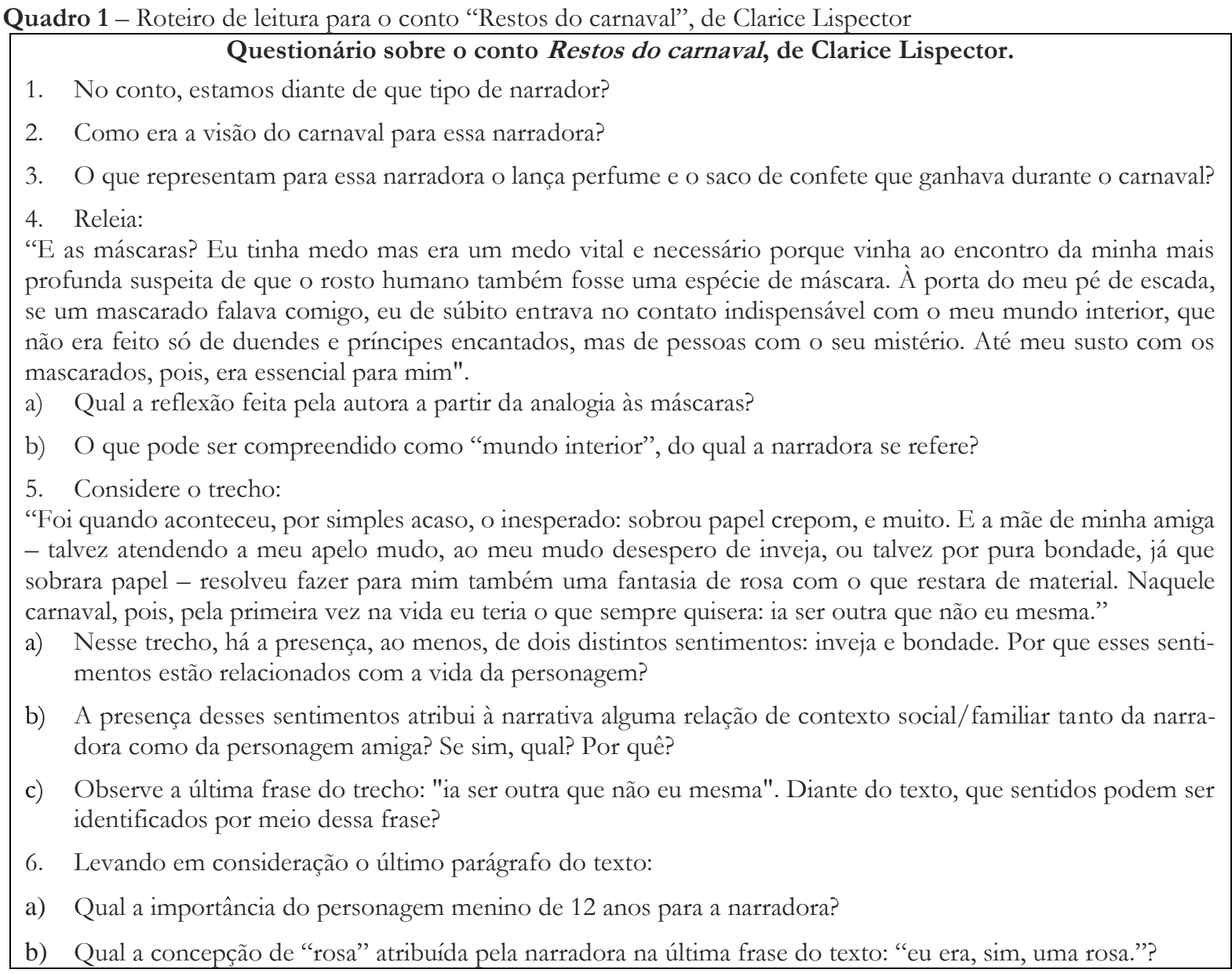
Fonte: Arquivos de estágio.

Para uma ação planejada e estratégica, o roteiro de leitura se torna um interessante instrumento para manutenção de uma leitura mediada, em cumprimento a objetivos traçados. Ele permite aguçar a percepção analítica do leitor, por meio dos questionamentos que apresenta e das suas possibilidades de construção. Nesse roteiro, por exemplo, convidamos, duas vezes, os leitores a focalizarem em trechos específicos do texto, de modo que, através da releitura, eles pudessem analisar aspectos importantes para a narrativa desenvolvida no conto. Obviamente, para obtenção de resultados positivos, o roteiro precisa ser elaborado com responsabilidade e com estratégias definidas, para não se tornar um mero espaço para preenchimento de respostas sem reflexão. Nesse sentido, a mediação oral do professor deve suscitar o debate, o compartilhamento de experiências com o texto, de desentendimento e de entendimento do enredo. As perguntas do roteiro, com isso, tornam-se um caminho para discussão, para que aspectos linguísticos, temáticos e estilísticos não sejam esquecidos.

É claro que quando resolvido por escrito, o roteiro de leitura também cumpre objetivos que dizem respeito à "concretização, a materialização da interpretação como ato de construção de sentido." (COSSON, 2006, p. 65). Não podemos esquecer que dentro do contexto escolar essa materialização é muito importante, uma vez que estamos formando indivíduos que, durante a vida, serão cobrados a registrarem por escrito leituras das mais diversas ordens e, por isso, precisam ser ins- 
truídos também nessa direção. Além disso, a materialização de respostas exige aos leitores retornar ao texto, relê-lo, analisá-lo com atenção, questioná-lo, compará-lo com outras experiências leitoras, compreendê-lo, o que pode permitir que outros sentidos sejam extraídos nessa relação e que os sensos crítico e estético sejam aflorados.

No roteiro em questão, enquanto instrumento para leitura compartilhada e posterior registro escrito de percepções e compreensões individuais, buscamos chamar a atenção para o tipo de narrador apresentado no texto, uma narradora-personagem, para elementos alegóricos que compõem o enredo narrativo, como o lança-perfume, o saco de confete, as máscaras e a rosa, e os efeitos de sentido atribuídos por esses elementos e pelas analogias construídas por meio deles. Também enfatizamos os sentidos que podem ser compreendidos em meio a trechos específicos da narrativa, em uma relação entre o que o texto apresenta e a percepção de mundo dos leitores.

Nessa direção, estratégias de leitura são exigidas aos leitores, a fim de que eles contemplem os objetivos desejados. As estratégias exigidas pelas perguntas do roteiro, em sua maioria, ultrapassam a simples identificação para alcançar principalmente inferências, que exigem um pouco mais de criticidade leitora e concordam com o nível escolar em que esses leitores estão submetidos.

Essas inferências ora cumprem função local (como a pergunta "b" da questão 4 e a pergunta "b" da questão 6), para, em relação ao contexto imediato do texto (cotexto) e aos significados já tidos para termos e/ou expressões, estabelecer novos significados, sentidos no interior de seu uso (ROJO, 2009). Na condição do texto literário, possibilita ampliar as noções significativas e estar atento aos sentidos conotativos empregados para obtenção de especificidades temáticas e estilísticas da narrativa.

Para a ativação de inferências globais (como as questões 2 e 3 , a pergunta "a" da questão 4, as perguntas "a", "b" e "c" da questão 5 e a pergunta "a" da questão 6), é preciso entender que nem tudo é posto explicitamente no texto. Por isso, os implícitos precisam ser compreendidos para uma leitura efetiva, o que exige dos leitores a observação das pistas deixadas pelo autor, os sentidos já construídos com a leitura e os seus conhecimentos de mundo, adquiridos ao longo de suas experiências (ROJO, 2009). Em se tratando de literatura, o implícito é algo muito recorrente para constituição de determinados efeitos estilísticos, principalmente quando lidamos com uma escrita introspectiva como nas narrativas de Clarice Lispector. Questionar aos leitores sobre esses sentidos implícitos é de fundamental importância para a análise coerente do texto literário e para a fruição estética.

No que diz respeito à ativação de conhecimentos de mundo, os leitores levam as informações adquiridas em suas vivências humanas para a leitura de novos textos e novas experiências leitoras. Ao considerar especialmente a narrativa de "Restos do carnaval", percebemos que os conhecimentos de mundo são essenciais, uma vez que um produto cultural, o carnaval, é trazido como ponto de partida temático para a construção de todo o enredo narrativo. Dessa forma, as compreensões que os leitores trazem sobre esse produto cultural são fundamentais para todos os possíveis efeitos de sentido que o texto pretenda exteriorizar, principalmente na relação entre o que é senso comum sobre esse produto e as significações atribuídas a ele pelo texto.

Quanto à leitura do curta-metragem, este foi exibido em sala de aula e debatido também em acompanhamento de roteiro de leitura que contribuísse para a percepção dos elementos narrativos que o constituíam. Observemos esse roteiro: 
Quadro 2 - Roteiro de leitura para o curta-metragem "Uma flor"

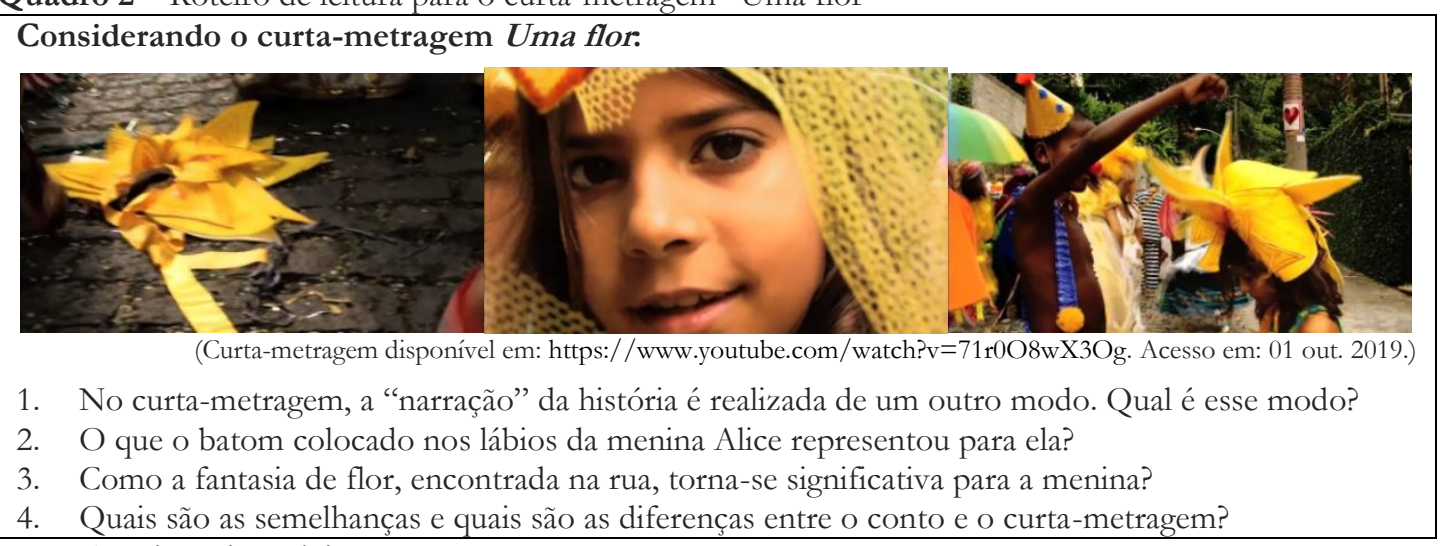

Fonte: Arquivos de estágio.

Esse roteiro de leitura cumpriu funções para a discussão e para a coleta de respostas escritas, assim como já explanado em relação ao roteiro do conto. Mais curto em extensão e com perguntas mais "abertas" às interpretações audiovisuais dos leitores, esse roteiro focalizou na forma de narração realizada nessa mídia, o que solicitava a percepção de como ações das personagens, focos de imagem, cores, trilha sonora, etc. estavam sendo utilizados para a contação do enredo em desenvolvimento. Além disso, chamava a atenção para os elementos alegóricos utilizados nesse texto, como o batom e a fantasia de flor, e para a comparação entre o texto fílmico e o texto escrito, que cumprem primordialmente um mesmo enredo, tendo em consideração as suas vinculações em nível de adaptação/baseamento do primeiro em relação ao segundo.

É importante destacar, conforme afirma Alcântara (2014), que o curta-metragem em sala de aula pode desenvolver uma aproximação com o processo de ensino e de aprendizagem, uma vez que a produção cinematográfica pode desencadear um movimento semelhante ao realizado ao assisti-la em outros espaços, com ativação de processos pessoais de assimilação e interpretação. Nessa direção, é possível que um conjunto de processos mentais, responsáveis pela compreensão ativa e por competências comunicativas dos alunos, seja acionado, em uma contextualização entre as situações narradas no texto fílmico e as suas realidades. Isso pode contribuir efetivamente para o processo interpretativo e associativo dos leitores diante do texto (ALCÂNTARA, 2014).

No roteiro de leitura para o curta-metragem "Uma flor", as estratégias exigidas aos leitores centram-se novamente na inferência de informações implícitas no texto, de modo a atingir as compreensões necessárias (como as questões 1, 2 e 3). Na questão 4, os leitores ainda são levados a acionar a estratégia de comparar informações presentes nos dois textos para identificar semelhanças e diferenças entre eles. Essa estratégia auxilia em uma melhor compreensão, na medida em que propõe aos leitores a comparação de informações de várias ordens, provenientes dos textos e também dos conhecimentos trazidos das experiências de mundo (ROJO, 2009).

Enquanto comparação de elementos literários que compõem as narrativas dos textos, as especificidades linguísticas, temáticas, estilísticas, imagéticas e auditivas precisam ser analisadas de forma minuciosa para que a construção de sentidos seja efetivada e os aspectos que se confrontam entre esses textos possam ser percebidos e exteriorizados. No que diz respeito ao texto fílmico, este passa a ser enxergado como uma adaptação, o que não demanda a fidedignidade a todo o enredo trazido pelo texto escrito. Nessa relação, é possível levar os leitores a analisarem o que é tratado como prioritário dentro do enredo e o que é considerado secundário, e que, por isso, pode ser alternado para enquadrar-se melhor à nova mídia.

A presença dessa comparação em sala de aula cumpre também as novas exigências da BNCC, que propõe o trabalho com textos de diversas semioses (visuais, verbais, sonoras, gestuais), a fim de analisar o funcionamento das linguagens utilizadas nelas. No Ensino Médio, a BNCC sugere a análise contextualizada de produções artísticas, como o curta-metragem, e de textos literários, como os contos de Clarice Lispector. Nessa direção, a apreciação de gêneros que vinculam obras 
artísticas e produções culturais em diferentes mídias, no que concerne ao contexto literário, possibilita práticas de letramento literário - e de letramento multissemiótico -, contribuindo efetivamente para a formação de leitores literários.

\section{CONSIDERAÇÕES FINAIS}

Neste trabalho, buscamos, mais que apresentar uma experiência de ensino no contexto de Estágio Supervisionado, refletir sobre estratégias para a formação de leitores literários, tanto com relação ao processo de mediação professor-leitores, como em relação ao processo de leitura leitores-textos. Nesse sentido, para o primeiro caso, defendemos que o uso dos gêneros conto e curtametragem, devidamente mediado com instrumentos e objetivos definidos, pode ser uma estratégica eficaz para a leitura literária em sala de aula. Como exemplo disso, a experiência proporcionada pela leitura do conto "Restos do Carnaval", de Clarice Lispector, e do curta-metragem "Uma flor" demonstrou uma prática de letramento literário positiva que favoreceu a fruição estética e o senso crítico, por meio da análise dos elementos multissemióticos que compõem esses textos em suas respectivas mídias.

Vale ressaltar que a apresentação dessa experiência não tomou o caminho da recepção atingida nos leitores, uma vez que nossas pretensões centraram-se na ação de, ao compartilhar o planejamento estratégico para a mediação dessa leitura literária, possibilitar a sua (re)utilização, ampliação e (res)significação. Na medida em que compartilhamos uma experiência, também refletimos sobre os lugares atribuídos à literatura, especialmente à leitura do texto literário, nas salas de aula reais do país e sobre os usos desse objeto de ensino para a formação escolar e humana dos alunos.

Sobre o segundo caso, demonstramos possibilidades de ativação de estratégias, de natureza metacognitiva, por parte dos leitores para obtenção da compreensão dos textos. Nessa experiência, em concordância com o nível escolar em que os leitores se encontravam, as estratégias exigidas partiam de maior complexidade e trabalho cognitivo, focalizando principalmente a inferência, o uso de conhecimentos de mundo e a comparação entre textos. Falando especialmente da comparação, para a sua realização, é necessário que os leitores compreendam cada texto individualmente para empreender percepções de semelhanças e diferenças entre as narrativas, o que se apresenta como um excelente e árduo trabalho interpretativo.

$\mathrm{Na}$ medida em que finalizamos este trabalho, defendemos ainda que as aulas de literatura podem ampliar o escopo das mídias utilizadas em sala de aula, atrelando-se à realidade multissemiótica em que nos inserimos. O texto fílmico, enquanto linguagem audiovisual, é uma das possíveis ampliações que podem ser realizadas e que tem muito a contribuir se pensarmos na aproximação que esse texto pode proporcionar aos leitores e às suas realidades, na medida em que, se tratado comparativamente, também os aproxima do texto escrito. Nesse contexto, as práticas de letramento literário estarão de acordo com a necessidade da fruição dos leitores e das demandas educativas, com análises linguísticas, temáticas, estilísticas, imagéticas e auditivas.

\section{REFERÊNCIAS}

ABDALA JÚNIOR, B. Introdução à análise da narrativa. São Paulo: Scipione, 1995.

ALCÂNTARA, J. C. D. de. Curta-metragem: gênero discursivo propiciador de práticas Multiletradas. Dissertação (Mestrado) - Universidade Federal de Mato Grosso, Instituto de Linguagem, Programa de pós-graduação em estudo de linguagem. Cuiabá: UFMT, 2014.

BARBOSA, B. T. Letramento Literário: sobre a formação escolar do leitor jovem. Educ. foco, Juiz de Fora, v. 16, n. 1, p. 145-167, mar./ago. 2011.

BORGES, I. A. B. G.; PAES, F. S. Leitura e literatura: o letramento literário como possibilidade de intelectualização. Aedos, Porto Alegre, v. 9, n. 21, p. 244-264, dez. 2017.

BORUCHOVITCH, E. Estratégias de aprendizagem e desempenho escolar: considerações para a 
prática educacional. Psicología Reflexao e Crítica, año/vol. 12, número 002 Universidade Federal do Rio Grande do Sul, Puerto Alegre, Brasil, 1999.

BRASIL. Base Nacional Comum Curricular (BNCC). Educação é a base. Brasília: MEC/CONSED/UNDIME, 2018. Disponível em: http://basenacionalcomum.mec.gov.br/images/BNCC_EI_EF_110518_versaofinal_site.pdf. Acesso em: 01 mar. 2020.

BRASIL. Ministério da Educação. Secretaria de Educação Básica. Orientações Curriculares para o Ensino Médio: linguagens, códigos e suas tecnologias. Brasília: SEB/MEC, 2006. Disponível em: http://portal.mec.gov.br/seb/arquivos/pdf/book_volume_01_internet.pdf. Acesso em: 01 mar. 2020.

BRASIL. Ministério da Educação. Secretaria. Parâmetros Curriculares Nacionais (Ensino Médio) - Linguagens, Códigos e suas Tecnologias. Brasília, 2000. Disponível em: http://portal.mec.gov.br/seb/arquivos/pdf/14_24.pdf. Acesso em: 01 mar. 2020.

CANDIDO, A. Vários escritos. 3.ed. revista e ampliada. São Paulo: Duas Cidades, 1995.

CAPES. Portaria $G A B N^{\circ} 38$, de 28 de fevereiro de 2018. Institui o Programa de Residência Pedagógica. Brasília: Capes, 2018.

CLARICE, L. Restos do carnaval. In: CLARICE, L. Todos os contos. Organização de Benjamin Moser. Rio de Janeiro: Rocco, 2016.

COSSON, R. Letramento literário: teoria e prática. São Paulo: Contexto, 2006.

FERREIRA, M. B. (Des)mascaramentos: um estudo dos contos de Clarice Lispector. Dissertação (Mestrado em Literatura Brasileira) - Faculdade de Filosofia, Letras e Ciências Humanas da Universidade de São Paulo. Departamento de Letras Clássicas e Vernáculas. São Paulo, 2018.

FIGUEIRA, A. P. C. Estratégias cognitivas/comportamentais de aprendizagem. Problemática conceptual e outras rubricas. Revista Iberoamericana de Educación, 2006.

GOTLIB, N. B. Teoria do conto. 11.ed. São Paulo: Ática, 2006.

KLEIMAN, A. Oficina de leitura: teoria e prática. 15.ed. Campinas, SP: Pontes Editores, 2013.

KOCH, I. V.; ELIAS, V. M. Ler e compreender. os sentidos do texto. São Paulo: Contexto, 2006.

NASCIMENTO, C. G. V. O. Nos tempos de Clarice: uma análise do tempo e do espaço no conto Restos do Carnaval. In: Anais do 50 Seminário do GEL. São Paulo, 2002. Disponível em: http://www.gel.hospedagemdesites.ws/estudoslinguisticos/volumes/32/htm/comunica/ci055.

htm. Acesso em: 01 mar. 2020.

ROCHA, E.; JÚNIOR, G.; FREITAS, R. (direção). Uma flor. Rio de Janeiro: Universidade Estácio de Sá, 2009 (11 min e $20 \mathrm{seg}$ ). Disponível em: https://www.youtube.com/watch?v=71r0O8wX3 Og. Acesso em: 02 mar. 2020.

ROJO, R. Letramentos Múltiplos: escola e inclusão social. São Paulo: Parábola Editorial, 2009. 